\title{
The Role of doping in the window layer on Performance of a InP Solar Cells USING AMPS-1D
}

\author{
Dennai Benmoussa $^{1}$, Hassane Ben Slimane, Hamlaoui Abderrachid \\ Physics laboratory in semiconductor devices, Department of Physics, University of Bechar, Algeria.
}

\begin{abstract}
The efficiency of indium phosphide solar cells might be improved by a wide-band-gap window layer. In this work we was simulated using the one dimensional simulation program called analysis of microelectronic and photonic structures (AMPS-1D). In the simulation, hole doping concentration of Ga0.1In0.9P window was varied fro $10^{18}$ to $10^{20}\left(\mathrm{~cm}^{-3}\right)$. The rest of layer's doping were kept constant, By varying thickness of window layer the simulated device performance was demonstrate in the form of currentvoltage $(I-V)$ characteristics and quantum efficiency $(Q E)$.
\end{abstract}

Keywords: GaInP, AMPS-1D, simulation, conversion, efficiency, quantum efficiency

\section{INTRODUCTION}

Indium Phosphide has an electronic velocity higher than Silicon but even than GaAs; for this reason it has possible applications in the high frequency range and power electronic devices. It is also characterized by a direct band gap, which encourages its use in optoelectronic devices. It has moreover the highest carriers lifetime among Zinc-blend structures based on III-V [1].

Window layers are quite important in improving the solar cell energy conversion efficiency. They help in effectively reducing the surface recombination at the emitter surface of the solar cell without absorbing the useful light required for the device. Unlike silicon, solar cells based on III-V compound semiconductors and related materials suffer from the lack of native passivating oxides and/or wide choice of suitable large bandgap energy window materials. Various window layer materials have been investigated for III-V compound semiconductor based solar cells [2].

The ternary compound $\mathrm{Ga}_{\mathrm{X}} \mathrm{In}_{\mathrm{X}-1} \mathrm{P}$ is a candidate window layer for InP solar cells, The steep slope of the band gap with change in lattice parameter for Ga0.1 In $0.9 \mathrm{P}$ suggests that a significant increase in window layer transparency could be achieved by only a small eviation of the lattice parameter from the lattice-matched value of $5.86 \mathrm{~A}$.

In this present work, a one dimensional simulation program called a analysis of microelectronic and photonic structures (AMPS-1D) [3] is used to simulate the Ga0.1In0.9P window for indium phosphide solar cell structure. Fig. 1 shows the schematic of solar cell design studied in this work. The aim of the simulation of InP solar cell structure was to check the device performance by varying the thickness of the Ga0.1 In $0.9 \mathrm{P}$ window layer. The device performance is mainly based on the material parameters, optical parameters, and electrical parameters of each layers used in the structure. In this simulation the required parameters of $\mathrm{Ga} 0.1 \mathrm{In} 0.9 \mathrm{P}$ window having a hole doping concentration $10^{20}\left(\mathrm{~cm}^{-3}\right)$. Twere taken from the elsewhere [4]. For the rest of the layers the standard parameters were used.

\begin{tabular}{|c|}
\hline P+ Ga0.1In0.9P (window) \\
\hline$p \quad$ InP \\
\hline n InP \\
\hline n+ Ga0.1In0.9P (BSF) \\
\hline
\end{tabular}

Fig. 1 - InP solar cell structure used for the simulation

\section{MODEL DISCRIPTION}

The AMPS software can operate in two distinct modes: the density of state (DOS) mode or the lifetime mode. A description of both modes can be found in the AMPS manual [4]; In essence, the lifetime mode accepts inputs in the form of carrier lifetimes, which are assumed constant, independent of light and voltage bias, and does not address the underlying recombination processes. The DOS mode allows the definition of multiple defect states, using densities, energy distributions, and capture cross-sections. Based on this information, the recombination current and defect occupancy is calculated using the Shockley-Read-Hall formalism. To model the charge transport processes in the present structure shown in Fig. 1, the drift-diffusion approach is used as a 
function of device length, $x$. The three main equations are: the Poisson's equation, continuity equation for free holes, and continuity equation for free electrons. Generally, the Poisson's equation is [6]:

$$
\frac{d}{d x}\left(-\varepsilon(x) \frac{d \psi}{d x}\right)=q\left[p(x)-n(x)+N_{D}^{+}(x)-N_{A}^{-}(x)+p_{t}(x)-n_{t}(x)\right]
$$

Where, $\psi$ is the electrostatic potential, $\mathrm{n}, \mathrm{p}$ are the concentrations of free electrons and holes, $n_{t}, p_{t}$ are the concentrations of trapped electrons and holes $N_{D}^{+}, N_{A}^{-}$are the concentrations of ionized donors and acceptors, $\varepsilon$ is the dielectric permittivity of semiconductor, and q is the electron charge.

The transport characteristics of an electronic device may be derived by the continuity equation for the holes and electrons. The continuity equations in steady state conditions are:

$$
\begin{aligned}
& \frac{1}{q} \frac{d j_{n}}{d x}=R_{n}(x)-G(x), \\
& \frac{1}{q} \frac{d j_{p}}{d x}=G(x)-R_{n p}(x)
\end{aligned}
$$

Where, $J_{n}, J_{p}$ are electron and hole current density, $R_{n}, R_{p}$ are electrons and holes recombination velocities for direct band-to-band and indirect transitions, and $\mathrm{G}$ is the optical generation rate which is expressed as a function of $x$ is,

$$
G(x)=-\frac{d}{d x} \sum_{i} \phi_{i}^{F O R}\left(\lambda_{i}\right)+\frac{d}{d x} \sum_{i} \phi_{i}^{R E V}\left(\lambda_{i}\right)
$$

where, $\phi_{i}^{F O R}$ and $\phi_{i}^{R E V}$ are, respectively, the photon flux of the incident light and the light reflected from the back surface at a wavelength, $\lambda$ of $i$ at some point $x$, depending on the light absorption coefficient, and the light reflectance in the forward and reverse direction. In our simulation, the reflection indices for the forward and reverse directions are 0 and 0.6 , respectively. The governing equations (1), (2), and (3) must hold at every position in a device, and the solution to these equations involves determining the state variables $\psi(x)$, the $n$ type quasi-Fermi level $E_{f n}$, and the $p$-type quasi-Fermi level $E_{f p}$ or, equivalently, $\psi(x), n(x)$, and $p(x)$,, which completely defines the system at every point $x$. Because the governing equations for $\psi(x), E_{f n}$, and $E_{f p}$ are non-linear and coupled, they cannot be solved analytically. There must be boundary conditions imposed on the set of equations.

The Newton-Raphson technique is used in AMPS-1D. To be specific, the solutions to equations (1), (2), and (3) must satisfy the following boundary conditions:

$$
\begin{gathered}
\psi(0)=\psi_{0}-V ; \\
\psi(L)=0 ; \\
j_{p}(0)=-q S_{P 0}\left[p_{0}(0)-p(0)\right] ; \\
j_{p}(L)=-q S_{P L}\left[p(L)-p_{0}(L)\right] \\
j_{n}(0)=-q S_{n 0}\left[n(0)-n_{0}(0)\right] \\
j_{n}(L)=-q S_{n L}\left[n_{0}(L)-n(L)\right]
\end{gathered}
$$

$S_{P 0}, S_{p L}, S_{n 0}$ and $S_{n L}$ appearing in those conditions are effective interface recombination speeds for holes and electrons at $x=0$, and $x=\mathrm{L}$.

AMPS-1D solves three coupled differential equations each subject to boundary conditions (equation. 5) and then calculates the electrostatic potential and the quasi-Fermi level for holes and electrons at all point in the solar cell. Once these values are known as a function of depth, it is straightforward to calculate the carrier concentrations, electric fields and currents, and device parameters like the open-circuit voltage $(V o c)$, shortcircuit current density $(J s c)$, fill-factor $(F F)$, and the efficiency $(\eta)$. These parameters define the performance of a solar cell.

The grid spacing was selected to be denser in the thinner top layers of the device, where more rapid changes are to be expected in the band structure. The grid point does not exceed the maximum limit of 2000. Selected biases were entered as necessary; by default AMPS calculates $Q E$ and band structure for thermodynamic equilibrium, maximum power point, and under open-circuit conditions. 


\section{EXPERIMRNTAL}

In this study, a one-dimensional numerical analysis tool, AMPS-1D, is used to create various solar cell models and obtain its results. In AMPS-1D, four different layers are required for the modeling. More layers can be added as long as the grid points do not exceed the limitation, viz. 200-grid points. The four layers that are used in this modeling is the P+ Ga0.1In0.9P (window), $\mathrm{p}-\mathrm{InP}, \mathrm{n}-\mathrm{InP}$ and $\mathrm{n}+\mathrm{Ga0.1} \operatorname{In} 0.9 \mathrm{P}$ (BSF). Table 1 and table 2 show the description for the parameters used in the simulation and the base parameter that are used throughout the study [10].

\begin{tabular}{|c|c|c|c|c|}
\hline $\begin{array}{l}\text { Layers } \\
\text { Parameters }\end{array}$ & $\mathrm{P}+\mathrm{Ga0.1} \operatorname{In} 0.9 \mathrm{P}$ & $\mathrm{p}-\mathrm{InP}$ & n-InP & $\mathrm{n}+\mathrm{Ga} 0.1 \operatorname{In} 0.9 \mathrm{P}$ \\
\hline Thickness(nm) & 100 & 200 & 500 & 100 \\
\hline Dielectricconstant, $\varepsilon$ & 12.36 & 12.50 & 12.50 & 12.36 \\
\hline $\begin{array}{l}\text { Electron mobility } \mu_{n} \\
\left(\mathrm{~cm}^{2} / \mathrm{Vs}\right)\end{array}$ & 1100 & 4000 & 4000 & 1100 \\
\hline $\begin{array}{l}\text { Hole mobility } \mu_{p} \\
\left(\mathrm{~cm}^{2} / \mathrm{Vs}\right)\end{array}$ & 35 & 150 & 150 & 35 \\
\hline $\begin{array}{l}\text { Carrier density, } n \text { or } p \\
\left(\mathrm{~cm}^{-3}\right)\end{array}$ & P:1E18-1E20 & P:5E16 & n:5E16 & n:1E19 \\
\hline $\begin{array}{l}\text { Optical band gap, } E_{g} \\
(\mathrm{eV})\end{array}$ & 1.39 & 1.35 & & 1.39 \\
\hline $\begin{array}{l}\text { Effective density, } N_{c} \\
\left(\mathrm{~cm}^{-3}\right)\end{array}$ & $3.89 \mathrm{E}+19$ & $5.7 \mathrm{E} 17$ & $5.7 \mathrm{E} 17$ & $3.89 \mathrm{E}+19$ \\
\hline $\begin{array}{l}\text { Effective density, } N_{v} \\
\left(\mathrm{~cm}^{-3}\right)\end{array}$ & $2.93 \mathrm{E}+19$ & $1.1 \mathrm{E} 19$ & $1.1 \mathrm{E} 19$ & $2.93 \mathrm{E}+19$ \\
\hline Electron affinity,$\chi(\mathrm{eV})$ & 4.33 & 4.38 & 4.38 & 4.33 \\
\hline
\end{tabular}

\begin{tabular}{|cr|}
\hline \multicolumn{2}{|c|}{ Front Contact Windows } \\
PHIBO & 1.36 \\
SNO & $1.00 \mathrm{E}+07$ \\
SPO & $1.00 \mathrm{E}+07$ \\
RF & 0 \\
\hline
\end{tabular}

\begin{tabular}{|lr|}
\hline Back Contact BSF \\
PHIBL & 0.035 \\
SNL & $1.00 \mathrm{E}+03$ \\
SPL & $1.00 \mathrm{E}+03$ \\
RB & 1 \\
\hline
\end{tabular}

Table 1:AMPS-1D parameters InP solar cell

The AM $1.5 \mathrm{G}$ photon flux was used for the illumination (Fig. 2). The number of incident photons / $\left(\mathrm{cm}^{2} / \mathrm{s}\right)$ was entered for wavelengths between $0.320(\mu \mathrm{m})$ to $940(\mu \mathrm{m})$, with a step size of $2 \mathrm{~nm}$. The front panel of AMPS-1D simulation for InP solar cell structure is shown in Fig. 3.

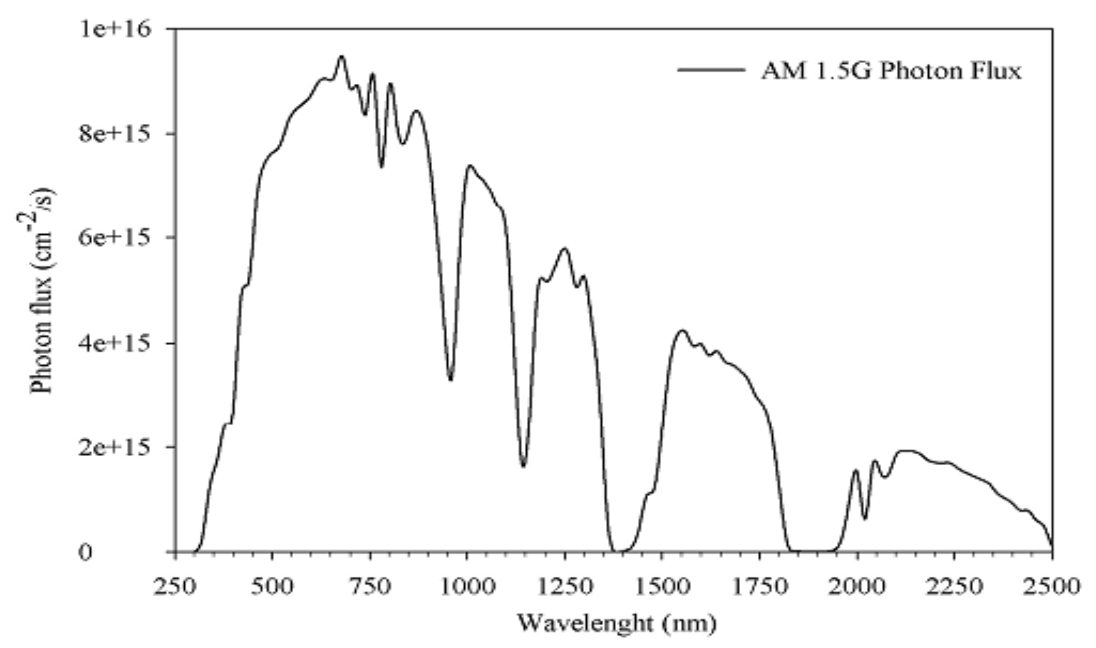

Fig. $2-A M 1.5 G$ photon flux as the illumination 


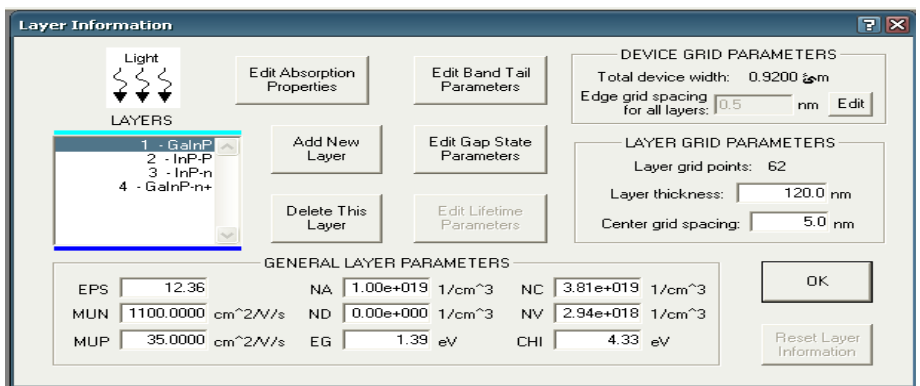

Fig. 3 -AMPS simulation front panel contains the device and layer grid parameters, and general layer parameters

\section{RESULTS AND DISCUSSIONS}

For that presented simulation, we have chosen a range of hole doping concentration between $10^{18}$ to $10^{20}\left(\mathrm{~cm}^{-3}\right)$ for window layer. The figure 4 schematizes the illuminated characteristics J-V of InP solar cell. According to these results, we notice a maximal density of current $(30.303 \mathrm{~mA} / \mathrm{cm} 2)$ for a value of the doping of the window layer $\mathrm{Na}=10^{18}\left(\mathrm{~cm}^{-3}\right)$ but for a maximal voltage $(1.104 \mathrm{~V})$ for a value of the doping of the Window layer $10^{20}\left(\mathrm{~cm}^{-3}\right)$.

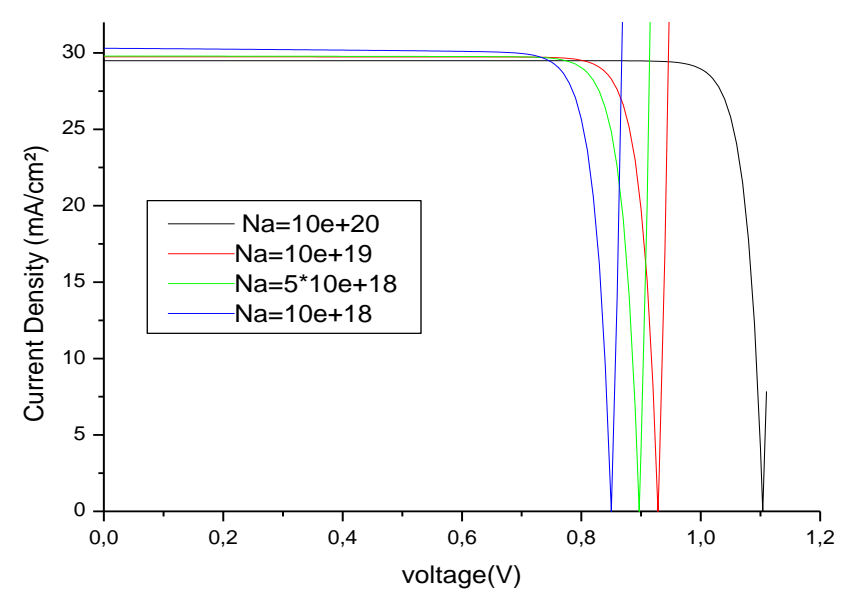

Fig. 4: The effect of doping of the window on the characteristics J-V

The spectral response $(\mathrm{QE})$ for different thicknesses window from AMPS-1D simulation is shown in fig. 4; the cell with window layers of the doping $10^{20}\left(\mathrm{~cm}^{-3}\right)$. maintains almost above $99 \%$ of QE for the whole visible range of spectra where it is confirmed better energy conversion performance of the cell.

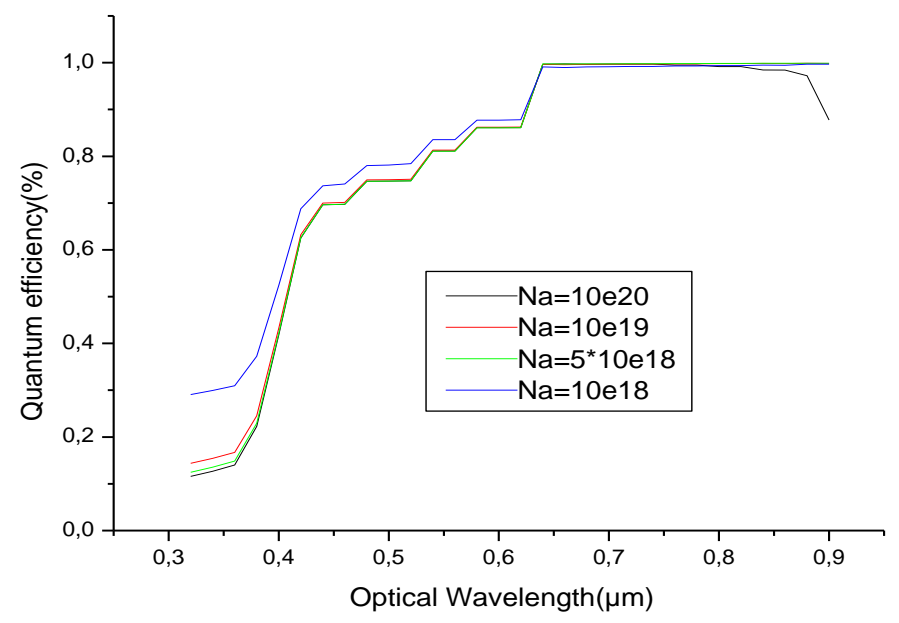


The effect of the doping window layer on cell performance such as effect on general performance parameters, quantum efficiency $(\mathrm{QE})$, shunt and series resistance, light and dark I-V characteristics. Characteristics of each cell with window a thickness are shown in the Table

\begin{tabular}{|c|c|c|c|c|}
\hline Thickness of window & $J_{s c}\left(\mathrm{~mA} / \mathrm{cm}^{2}\right)$ & $V_{o c}(V)$ & $F F \%$ & $E_{f f} \%$ \\
\hline $\mathrm{Na}=10 \mathrm{e}+18$ & 30.303 & 0.850 & 85.8 & 22.114 \\
\hline $\mathrm{Na}=5 * 10 \mathrm{e}+18$ & 29.795 & 0.897 & 87.0 & 23.257 \\
\hline $\mathrm{Na}=10 \mathrm{e}+19$ & 29.744 & 0.928 & 87.5 & 24.156 \\
\hline $\mathrm{Na}=10 \mathrm{e}+20$ & 29.489 & 1.104 & 89.0 & 28.986 \\
\hline
\end{tabular}

\section{CONCLUSIONS}

We used AMPS-1D to investigate the dependence of the thickness window layer $(\mathrm{Ga} 0.1 \operatorname{In} 0.9 \mathrm{P})$ for $\operatorname{InP}$ solar cells. We demonstrated the effect of doping in window layer on the parameters of solar cells as opencircuit voltage $(\mathrm{Voc})$, the short-circuit current density $\left(J_{s c}\right)$, the conversion efficiency $E_{f f}$ the quantum efficiency $(\mathrm{QE})$. The conversion efficiency increased until hole doping concentration of Ga0.1In0.9P reaches around $10^{20}\left(\mathrm{~cm}^{-3}\right)$. Further increase of doping shows no improvement in efficiency. Similarly QE response is almost overlapping after the $10^{20}\left(\mathrm{~cm}^{-3}\right)$ toping layer window. These observations led to the conclusion that for the optimal performance of the solar cell device the hole doping concentration of layer plays a role.

\section{Acknowledgements}

We would like to acknowledge the use of AMPS-1D program that was developed by Dr. Finish's group at Pennsylvania State University (PSU).

\section{REFERENCES}

[1] M. Yamaguchi, C. Uemura and A. Yamamoto, J.Appl. Phys., 55, pp. 1429, 1984.

[2] J. Lammasniemi, R. K. Jain, M. Pessa, "Status of Window Layers for III-V Semiconductor Cells",Proceedings 14th European Photovoltaic Solar Energy Conference (1997) p. 1767.

[3] S.J. Fonash, A manual for One-Dimensional Device Simulation Program for the Analysis of Microelectronic and Photonic Structures (AMPS-1D), (The Center for Nanotechnology Education and Utilization, The Pennsylvania State University, University Park, PA 16802).

[4] M. J. Ludowise, W. T. Dietze, R. Boettcher and N. Kaminar, "High-Efficiency (21.4\%) Ga0.75In0.26As/GaAs (Eg=1.15 eV) Concentrator Solar Cells and the Influence of Lattice Mismatched on Performance”, Appl. Phys. Lett., Vol. 43, p. 468 (1983).

[5]. S.M. Sze Physics of semiconductor devices (New York: John Wiley \& Sons Press: (1981).

[6]. H.W. Schock, K. Bogus, in: J. Schmid, H.A. Ossenbrink, P. Helm, H. Ehmann, E.D. Dunlop (Eds.), Proceedings of the 2nd World Conference on Photovoltaic Energy Conversion, E.C. Joint Research Centre, Luxemburg, art. No. 3586 (1998). 